\title{
De quando vi a Beija-Flor e pensei: "Mire-se no exemplo dessa escola de samba" e, após escrever o texto, lembrei-me da gravura $E l$ sueño de la razón produce monstruos, de Goya ${ }^{1}$
}

\author{
Enrique Mandelbaum ${ }^{2}$
}

Parece-me de fundamental importância hoje trabalhar com palavras-chave na Psicanálise - conceitos, se se quiser -, amplas o suficiente para abordar as múltiplas variações psicanalíticas em suas aplicações diárias em nossa clínica pessoal, em nossa cidade, em nosso país, na América do Sul, no mundo. Num texto anterior, defendi a ideia de que todo psicanalista deve constituir em si um objeto psicanalítico reparador - o objeto interno síntese em atividade em sua formação, em sua clínica e em sua teorização. O objeto psicanalítico reparador é uma palavra-chave ampla. É o/a mesmo/a analista que se forma, que realiza a sua clínica com seus pacientes, e é ele/ela também que tenta teorizar, isto é, transferir a outros a sua realização como psicanalista, a sua clínica. Estas três dimensões - a da formação pessoal, do trabalho na clínica e da teorização sobre a clínica - são, se quisermos dizer assim, nada mais do que vértices diferenciados da atividade do mesmo objeto, o objeto psicanalítico reparador, que é sempre orientado pela metapsicologia pessoal que conseguimos interiorizar a partir de nossa análise/autoanálise, do estudo dos textos psicanalíticos e das realizações de nossa clínica. Em qualquer momento que matutemos em "psicanalês", estamos psicanalisando, o que quer dizer - à medida que formos integrando de forma mais perfeita o objeto psicanalítico, pelo enraizamento mais profundo de uma metapsicologia pessoal -, estamos sendo psicanalistas. Ser psicanalista é viver mobilizado por uma metapsicologia pessoal. E falar da construção de uma metapsicologia pessoal não implica expressar um aprimoramento de si próprio. É antes de mais nada um processo de alfabetização emocional, cognitiva e racional, íntima e pessoal. Implica em reconhecer internamente que Freud nos explica e explica o mundo pelo menos um pedacinho de bom tamanho -, ao abranger desde a nossa intimidade mais

\footnotetext{
${ }^{1}$ Este trabalho foi apresentado em "Trabalhos livres" no I Simpósio Bienal "O mesmo, o outro: Psicanálise em movimento" da Sociedade Brasileira de Psicanálise de São Paulo.

2 Membro filiado do Instituto Durval Marcondes
} 
desconhecida até a nossa identidade mais exposta, mais exibida, no interior da psicodinâmica mobilizada em nossas psicopatologias da vida cotidiana.

O objeto psicanalítico reparador implica, sim, para a sua efetiva realização, uma batalha prática, um gesto interpretativo bem feito, seja no campo da análise pessoal, na elaboração teórica psicanalítica ou no trabalho na clínica, com o/a paciente. Talvez, se pensarmos no modelo da introjeção e da projeção na construção do/a psicanalista em nós, o objeto psicanalítico reparador se apresentaria, a partir de um vértice introjetivo - receptivamente ativo -, como metapsicologia e, na sua dimensão projetiva, isto é, realizadora de um ato reflexivo ou prático, como gesto interpretativo. (A continência imprescindível para a apreensão do fenômeno psicanalítico, tanto na clínica quanto no trabalho de análise pessoal e de teorização psicanalítica, nunca deixa de ter uma parcela de realização interpretativa.)

Todo/a psicanalista é mobilizado por uma interpretação profunda em atividade. Boa parte das fantasias inconscientes de um/a psicanalista deve ter ganhado a condição de poder transfigurar-se em fantasias psicanalíticas. Melanie Klein diz mais ou menos isto quando nos informa, em seu texto "As origens da transferência" (1952), que "somente através da ligação contínua das experiências mais recentes com as anteriores e vice-versa (e isto significa um trabalho árduo e paciente), somente explorando consistentemente a interação dessas experiências, é que o presente e o passado podem se aproximar na mente do paciente" [e, aqui em nosso texto, na mente de todo/toda psicanalista]. E continua a citação: "Este é um aspecto do processo de integração, o qual, à medida que a análise progride, abrange a totalidade da vida mental do paciente" [em nosso caso, do/a psicanalista]. E ela conclui, mais adiante: "Tudo isso implica que a vida de fantasias inconscientes, menos radicalmente separada da parte inconsciente da mente, pode ser mais bem utilizada em atividades do ego, tendo como consequência um enriquecimento geral da personalidade" (p. 79). É a realização desta elaboração descritiva de Melanie Klein que queremos manifestar ao dizer que boa parte de nossas fantasias inconscientes ganha, através da construção de nossa metapsicologia pessoal, a condição de emergirem como fantasias inconscientes psicanalíticas. 
Não devemos esquecer que o objeto psicanalítico reparador só se realiza em gesto prático e/ou reflexivo no interior de um círculo hermenêutico psicanalítico que nada mais é do que a própria circunstancialização da atividade desse objeto, sua realização na vida prática, tanto na dimensão da intimidade subjetiva quanto na da intimidade objetivada. Falar de círculo hermenêutico psicanalítico é falar das circunstâncias e das realizações do matutar psicanalítico. Circunstancializar o círculo hermenêutico psicanalítico suscita a demanda de levar em consideração, na construção de nossa metapsicologia, as vicissitudes de nossa biografia pessoal, isto é, de nossa história familiar, e o impacto da história psico-sociocultural, política e econômica do país em que estamos inseridos, o que quer dizer, em nosso caso, que entre nós e o Freud que sonhamos realizar, e para além da história dos processos e transformações interpretativos da própria Psicanálise, existe a história concreta do cotidiano brasileiro. Não é apenas que nós lemos Freud em Português, numa versão/tradução específica. Mas que nós lemos no interior de um cotidiano brasileiro, isto é, num mergulho na história dos profundos processos que organizam a vida brasileira. Tudo isto é para dizer que nós não lemos Freud em via direta. Já os primeiros psicanalistas sabiam disto. Terem sentido a necessidade de criar uma edição standard - a Standard Edition da obra freudiana - é exatamente uma realização na tentativa de acompanhar com mais sucesso a possibilidade de preservar o núcleo freudiano o mais firme possível diante das poderosas forças circunstanciais cotidianas, sempre em atividade em qualquer contexto histórico em que se leva adiante o trabalho psicanalítico. A edição standard é uma espécie de lastro histórico metapsicológico da teoria freudiana diante de sua inevitável transformação cotidiana, nos diversos contextos sócio-histórico-culturais e ao longo do passar dos anos.

Se estamos certos, o Freud que nós lemos e o Freud que nós realizamos na construção de nossa metapsicologia pessoal assume sempre uma condição histórica, mais ou menos reconhecida de forma consciente. Expliquemos melhor, e acho que o desfile da Escola de Samba Beija-Flor no último Carnaval pode nos ajudar. O que eles apresentaram foi uma leitura do clássico de ficção inglesa Frankenstein, de Mary Shelley. Mas o que eles efetivamente realizaram foi uma espécie de exibição muito pessoal e bem feita, isto é, rica em múltiplos níveis de sentido, da nossa realidade brasileira. A escola de samba também se serviu de uma autora estrangeira, inglesa, tal como nós nos servimos de autores estrangeiros - Freud, Klein, Bion, Lacan - em nossa prática. A Beija-Flor se 
enredou com maestria no interior do texto de Mary Shelley. E desse enredamento pôde emergir, em samba-enredo, a possibilidade de nomear a nossa realidade atual como monstruosa e, principalmente, por em cena a nossa responsabilidade com este estado de coisas e nossas respostas ambivalentes, por todos os meios. No enredo, esse violento afastamento da realidade- psicanaliticamente falando, a atividade dos processos de negação -, foi representado pelo incrível e inesperado carro alegórico logo na abertura do desfile: um bloco de gelo. O enredo da Beija-Flor apresentava a realidade brasileira como monstruosa e nos colocava como sujeitos incapazes de lidar com a monstruosidade pela qual, de alguma forma, somos responsáveis. Mas o enredamento da Beija-Flor na obra Frankenstein era mais pleno. A própria escola de samba parecia assumir sua condição de Frankenstein nessa integração nem sempre bem acabada de retalhos, penas, batuques, realidades, fantasias, paetês, lantejoulas, corpos e cuícas, compondo o todo um frágil e quebradiço ritmo intenso e marcante, feito para só durar naquele momento.

Talvez devêssemos assumir o que há de Frankenstein no Freud que estamos acostumados a receber nos cursos de formação psicanalítica no Brasil nos dias de hoje, seja nas sociedades de psicanálise ou em outros centros de formação. O próprio Freud abre seu texto $O$ mal-estar na civilização, dizendo: "é impossível fugir à impressão de que as pessoas comumente empregam falsos padrões de avaliação - isto é, de que buscam poder, sucesso e riqueza para elas mesmas e os admiram nos outros, subestimando tudo aquilo que verdadeiramente tem valor na vida" (p. 81). Verdade que, a seguir, é o próprio Freud que vai relativizar posições tão amplas quanto esta. Mas, o que nos interessa é a apreensão parcial a que estamos sujeitos. Os recortes muitas vezes tergiversam, podem se desviar das ideias centrais. Vou dar dois exemplos de algo muito frequente em ação na transmissão de Freud nos dias de hoje, entre nós. Um é a seriedade com que é tratado o uso, por Freud, de dois termos: o de Trieb e o de Instinkt, ambos utilizados por ele de forma complementar, para dar conta das forças dinamizadoras que mobilizam a atividade psíquica. Para Freud, é essencial que a atividade psíquica seja tão orgânica e natural quanto o sistema digestivo ou o sistema respiratório. Nem tanto pelas implicações fisiológicas, mas sim pelas implicações psicobiológicas, às quais Freud sempre esteve atento. Agora, é óbvio - e é isto que ele tenta mostrar o tempo todo - que as forças psíquicas são dotadas de uma plasticidade ausente nos instintos fisiológicos mais básicos. Esta é a descoberta freudiana. O que chama a atenção na leitura dos psicanalistas da Trieb 
é a pureza que pregam. De acordo com eles, algo básico que todo/toda psicanalista deve reconhecer, antes de mais nada, é que Trieb não é instinto. E, como não tem uma palavra em Português adequada, que seja pulsão. O que estes/estas psicanalistas demandam é a total autonomia da vida psíquica em relação ao que nós poderíamos chamar de funções vitais.

Uma segunda vertente importante de transmissão da obra freudiana entre nós é aquela que pretende prioritariamente ensinar ao/à psicanalista a importância dele/dela abrir-se para o sonho, como se a obra de Freud fosse, antes de tudo, uma hermenêutica onirizante, isto é, que o sonho é o princípio, o meio e o fim de tudo. Não se escuta sem sonhar e não se interpreta sem sonhar. Claro que aqui também, tal como no caso dos puristas da Trieb, existe um fundo de verdade, neste caso amplificado pela singular leitura psicanalítica de Bion (no caso da Trieb, as fontes são francesas, em especial a escola de Lacan). O que ocorre no caso da hermenêutica onirizante é que se toma Bion como sendo a mais perfeita tradução da obra freudiana.

Em ambos os casos, eu percebo algo de Frankenstein. Não tanto no sentido de que a obra freudiana fique transfigurada - isto é óbvio para quem estuda Freud de forma mais direta e aberta. Estou me referindo ao Frankenstein da Beija-Flor. Em ambas as hermenêuticas, existe ao mesmo tempo uma complementariedade brasileira, isto é, uma circunstância histórica em atividade nas leituras propostas. Na primeira, talvez toda uma tradição antropofágica que implica algo assim como a construção de uma singularidade apesar da realidade em que vivemos - uma espécie de vida sem história, ou vida para além da história, ou de desejo sem corpo biologicamente determinado - a utopia de um se fazer arrancando-se da história. No segundo caso, fora o recolhimento onírico, talvez a tradição hermenêutica em atividade mais marcante seja a do Positivismo, em sua vertente de crença no progresso da Ciência. Bion seria o progresso final de Freud, sua versão mais bem acabada, como dizíamos antes. Quem estuda Bion, já introjeta o essencial de Freud. Ambas as leituras tendem a criar uma prática que, por assim dizer, se dá apesar do Brasil e não propriamente no Brasil. É isto que me lembrou o samba-enredo da Beija-Flor, cujo tema principal era o desamparo e o abandono. Tem um bom pedaço da obra freudiana 
que vive desamparado e abandonado entre nós. O próprio conceito de ego, por exemplo. Tanto para uma leitura puramente pulsional quanto para a hermenêutica onirizante, o ego fica identificado com o $e u$ da linguagem, o eu enunciador e, portanto, fundamenta a subjetividade no exercício da língua. Este não é o ego freudiano. $\mathrm{O}$ ego freudiano, ou o $e u$ freudiano, por estar completamente aberto ao Id, isto é, às diversas manifestações do inconsciente, suporta sempre a subjetividade no hífen entre a psique e o soma, no hiato entre o desejo e o corpo, entre a intimidade e a história, no interior de uma materialidade vital, orgânica, natural. No mesmo texto $O$ mal-estar na civilização, Freud tenta acompanhar o desenvolvimento do sentimento do eu no adulto: "deve ter passado por um processo de desenvolvimento que, se não pode ser demonstrado, pode ser construído com um razoável grau de probabilidade” (p. 84). O pensar psicanalítico é um pensar profundo, é um pensar a subjetividade e o mundo sem temer se perder na mistura de ambos, para logo a seguir saber separá-los, reconhecendo o que é de um e o que é do outro. O estudo das relações de objeto na Psicanálise nos ensina que todos somos, desde um princípio, um e dois, isto é, um sujeito ligado. Para dar conta da construção deste sentimento de ego desde as suas raízes infantis até a vida adulta, em $O$ mal-estar na civilização Freud escolhe como exemplo a cidade de Roma, a cidade eterna. Ele mostra a precariedade como o remoto passado se preserva em sítios históricos concretos, mas - e aqui ele é Freud em seu núcleo mais próprio - afirma ele, supondo "que Roma não é uma habitação humana, mas uma entidade psíquica, com um passado semelhante, longo e abundante isto é, uma entidade em que nada do que outrora surgiu desapareceu e onde todas as fases anteriores do desenvolvimento continuam a existir paralelamente à última" (p. 88). O que Freud está defendendo é que o $e u$ que a metapsicologia põe em atividade é mais amplo do que apenas o $e u$ da linguagem, pura subjetividade em construção. $\mathrm{O} e u$ freudiano abarca também a materialidade da história já vivida, de um passado que não se reduz a arquivo, mas a uma experiência de vida, um testemunho vivido. $\mathrm{O}$ objeto psicanalítico reparador deve pretender dar voz e gesto também a esse testemunho e, no nosso caso, esse testemunho abarcará também a manifestação do desamparo e do abandono em andamento em nossa história, o modo como concebemos a lei, os aparelhos de Estado e o modo de viver e pensar a cidadania. Isto é imprescindível para falar de Édipo no Brasil. Quanto mais lermos Freud, mais brasileiros seremos, como a Beija-Flor em sua feliz leitura de Mary Shelley, em 2018. 


\section{Referências}

Desfile da Escola de Samba Beija-flor de Nilópolis 2018. https://www.youtube.com/watch?v=icQWIaimNVM.

Freud, S. (1930) O mal-estar na civilização. Em: Edição Standard das Obras Psicológicas Completas de S. Freud, vol. XXI. RJ: Imago, 1976.

Klein, M. (1952) As origens da transferência. Em: Obras Completas de Melanie Klein: Volume III, Inveja e gratidão e outros trabalhos. (1946-1963). Rio de Janeiro: Imago, 1991.

Shelley, M. (1818) Frankenstein. RJ: Zahar, 2017. 